Madrygal. Revista de Estudios Gallegos

ISSN: 1138-9664

\title{
La grabación de música gallega y asociada a ella en Buenos Aires (1907-2015)
}

\author{
Norberto Pablo Cirio $^{1}$
}

Recibido: 4 de febreiro de 2016 / Aceptado: 6 de outubro de 2016

Resumen. A partir de documentos compilados e información generada por el autor desde 1996 se presenta un panorama de la grabación de música gallega y asociada a ella en Buenos Aires entre 1907 y 2015, cuya cifra asciende a 1540 registros. El artículo analiza las estrategias multidireccionales entre el mercado discográfico local, el de esta colectividad y el de la Galicia territorial. Se da cuenta de los sellos discográficos propios, la docena de soportes existentes y los tipos de conformaciones instrumentales en que pueden clasificarse los 289 grupos y solistas existentes en el país desde 1878 desde un punto de vista cuantitativo y cualitativo y en perspectiva diacrónica. Las conclusiones se elaboran teniendo en cuenta las características de esta fuente primaria y atendiendo a la atribución del significado simbólico de los productores y consumidores de esta música en el marco de la migración gallega a la Argentina.

Palabras clave: Música gallega; discografía; Argentina; inmigrante.

\section{[gl] A gravación de música galega e asociada a ela en Bos Aires (1907-2015)}

Resumo. A partir de documentos e información rexistrados polo autor desde 1996 preséntase un panorama da gravación de música galega e asociada a ela en Bos Aires entre 1907 e 2015, cuxa cifra ascende a 1540 rexistros. O artigo analiza as estratexias multidireccionais entre o mercado discográfico local, o desta colectividade e o da Galicia territorial. Dáse conta dos selos discográficos propios, a ducia de soportes existentes e os tipos de conformacións instrumentais en que poden clasificarse os 289 grupos e solistas existentes no país desde 1878 desde un punto de vista cuantitativo e cualitativo e en perspectiva diacrónica. As conclusións elabóranse tendo en conta as características desta fonte primaria e atendendo á atribución do significado simbólico dos produtores e consumidores desta música no marco da migración galega á Arxentina.

Palabras chave: Música galega; discografía; Arxentina; inmigrante.

\section{[en] Galician Music Recording and Associated with it in Buenos Aires (1907-2015)}

\begin{abstract}
From data and documentation collected by the author since 1996, we present the landscape of the recording of Galician music and aspects associated to it in Buenos Aires between 1907 and 2015, whose number goes up to 1,540 records. The article analyzes multidirectional strategies between the local recording market, that of this community, and that of territorial Galicia. We also account for their own recording companies, the dozen existing formats, and the types of instrumental configurations in which the 289 existing groups and soloists in the country since 1878 can be classified from a quantitative and qualitative approach, and from a diachronic perspective. Conclusions are elaborated taking into account the characteristics of this primary source and paying special attention to the attribution of symbolic meaning given by producers and consumers of music implicated in the framework of Galician immigration to Argentina.
\end{abstract}

Keywords: Galician Music; Discography; Argentina; Immigrant.

Sumario. 1. Panorama general. 2. Música gallega. La grabación como vivencia social. 2.1. Las discográficas gallegas. 2.2. Galicia-Buenos Aires-Galicia. 3. Las conformaciones musicales en perspectiva diacrónica. 4. Conclusiones. 5. Referencias discográficas. 6. Referencias bibliográficas.

Como citar: Cirio, P. N. (2017): "La grabación de música gallega y asociada a ella en Buenos Aires (1907-2015)", Madrygal. Revista de Estudios Gallegos 20 (Núm. especial), pp. 41-57.

1 Instituto Nacional de Musicología “Carlos Vega”, Buenos Aires.

E-mail: pcirio@fibertel.com.ar 


\section{Panorama general}

El patrimonio musical gallego en la emigración se mantiene tanto en la práctica consuetudinaria de los emigrados y sus descendientes, de manera amateur y profesional, como en diversos soportes, entre ellos las placas discográficas. En mi investigación sobre esta música en la Argentina, iniciada en 1996, procuro trabajar ambos cauces. Las placas -mayormente producidas en Buenos Aires y con fines comerciales- son cuantiosas. A partir de la imprescindible tarea de rastreo, localización, indización y, excepto en los CDs, digitalización, su estudio puede iluminar a esta colectividad en tanto realizadora, comercializadora y consumidora de música pues, en el caso de la que reconocen como propia, constituye uno de sus pilares generadores de sentimientos de pertenencia etnocultural, que en este grupo usualmente se resume con el término galleguidad. En este artículo deseo presentar el corpus discográfico producido en Buenos Aires que he podido documentar (1540 registros producidos entre 1907 y 2015) siguiendo algunos parámetros para su indización desde la antropología de la música, por ejemplo de cara a su uso como marcador etnicitario, relevancia social y medio para la construcción identitaria (Martí i Pérez 1995 y 1996, Frith 2000, Pelinski 2000) atendiendo al caso gallego en general (Costa Vázquez 2001). Me interesa analizar cómo la colectividad gallega de Buenos Aires ha venido sirviéndose de la industria discográfica para expresarse identitariamente, privilegiando en ciertos contextos ciertas temáticas y agrupaciones. En este marco los cambiantes escenarios de lo que sucedía en Galicia y la Argentina han venido desempeñando una labor estimulante o limitante de este mercado.

A lo largo de la historia de la grabación, que tras varios intentos en Francia tomó impulso en 1877 en Estados Unidos de América con el invento del fonógrafo por Thomas Alva Edison, la industria discográfica ha ensayado $-y$ sigue ensayando- diversos soportes para su preservación a fin de optimizar cuantitativa y cualitativamente su almacenamiento-distribución y consumo, afectando la relación de estas cuestiones con la situación de partida, la producción (Day 2000, Tylor 2001, Cámara de Landa 2003). Dado el período económico de bonanza que tenía la Argentina finisecular, aquí la fonografía comenzó tempranamente, datando las primeras grabaciones de 1896. Destinadas a un incipiente público que se moldeaba acorde la industria del entretenimiento incorporaba esta modalidad de socialización para atender la globalizante cultura del espectáculo (Ochoa 2003: 37), tras la apertura de filiales de muchos sellos europeos y estadounidenses, hacia 1904 o 1905 abren las primeras discográficas locales (García Muñoz, Goyena y Vigo 1999, Elías 2015). Desde el comienzo esta industria se caracterizó por su eclecticismo temático y autoral, pues procuraban ofrecer la mayor variedad posible de músicas (inter)nacionales, pasadas y presentes, populares y académicas ("clásicas"), lo que incluyó compositores gallegos y música gallega, generalmente subsumida dentro de los ítems España y folclore español.

Este estudio de caso se basa en los 1540 registros reunidos en mi archivo, de los cuales 1399 fueron grabados en Buenos Aires; de éstos 1312 están editados y 87 son másters que, por diversos motivos, no llegaron a comercializarse. Puesto que en la historia de la industria discográfica algunos soportes se superponen, con cierto criterio diacrónico este corpus tiene 12 tipos:

\begin{tabular}{|l|r|} 
Tipo de soporte & Registros \\
\hline 1. Rollo de pianola & 13 \\
2. Disco de pasta de $25 \mathrm{~cm}, 78 \mathrm{rpm}$ & 266 \\
3. Disco de pasta de de $26,9 \mathrm{~cm}, 78 \mathrm{rpm}$ & 8 \\
4. Disco de pasta de $30 \mathrm{~cm}, 78 \mathrm{rpm}$ & 20 \\
5. Disco de acetato de $20 \mathrm{~cm}, 33 \frac{1}{3} \mathrm{rpm}$ & 4 \\
6. Disco de acetato de $20 \mathrm{~cm}, 78 \mathrm{rpm}$ & 7 \\
7. Cinta abierta & 13 \\
8. Disco de vinilo de $331 / 3 \mathrm{rpm}$ LP & 171 \\
9. Disco de vinilo de $33^{1} / 3 \mathrm{rpm}$ simple & 129 \\
10. Disco de vinilo de $45 \mathrm{rpm}$ simple & 7 \\
11. Casete & 105 \\
12. Disco compacto & 656 \\
\hline
\end{tabular}

Un estudio de la música gallega en la inmigración como este requiere problematizar el concepto mismo de música gallega. Considero a la música una actividad indisolublemente ligada a la sociedad en que se halla inserta y siendo, por tanto, un encapsulamiento de formas cognitivas y de valores compartidos cuyos rasgos revisten particulares significados de sentido (McLeod y Herndon 1980). Como toda práctica cultural, es un constructo que cambia en el tiempo y, lejos de tener cualidad ontológica, su valor simbólico reposa en el sentido que le dan sus cultores vía los procesos de interpelación o narratividad (Pelinski 2000: 
163-175) en el marco de su representación etnicitaria que, además, se articula diferente esté el gallego viviendo en su tierra o en la emigración, espacio social donde su descendencia deberá atender también a otras lealtades étnicas y musicales (Kirshenblatt-Gimblett 1992, Costa Vázquez 2001). En esta línea Martin Stokes (1994) señala que estas variables se complejizan acorde los individuos y los grupos implicados se articulen según parámetros, como el sexo, la edad o clase social. Como no me referiré aquí a la música practicada en Galicia sino por su colectividad históricamente más numerosa en el exterior, implica atender cuestiones particulares, por ejemplo la convivencia de sus cultores con géneros locales, como el tango, lo que dio lugar a un cauce creacional $\mathrm{y}$ vivencial sui géneris. Es por ello que diferencio, como expreso en el título del artículo, entre música gallega y vinculada a Galicia. De este modo delimito siete variantes, ocupándome en este artículo sólo de las dos primeras:

\section{Música gallega interpretada y editada en} la Argentina (por gallegos o no). Comprende la mayoría de los registros. Un ejemplo es la grabación más antigua documentada, un disco de pasta de $78 \mathrm{rpm}$ de 1908, con la Alborada de Montes y Rebeirano [sic] de Porriño por el gaitero Manuel Dopazo Gontade. Fue grabado sólo cuatro años más tarde que las primeras efectuadas en Galicia por el coro Aires d'a Terra. Dado que esta investigación se encuentra en curso, es probable que aparezcan grabaciones anteriores.

2. Música gallega interpretada en el exterior y editada en la Argentina. Dada la gran cantidad de inmigrantes gallegos inmigrados al país y el escaso desarrollo de la industria discográfica española hasta bien entrado el siglo XX, varios grupos de Galicia editaron sus placas en Buenos Aires, ciudad además pujante económicamente y con florecientes sellos, algunos incluso propiedad de gallegos y destinados a tal fin. Así, el violinista Manuel Quiroga grabó por lo menos cuatro obras en dos discos de 78 rpm y grupos de Galicia como el Real Coro Toxos e Froles y la Banda La Lira fueron editados por Hermifono, una discográfica de la colectividad.

3. Música gallega interpretada en la Argentina y editada en el exterior. En una suerte de camino a la inversa de la variante 2 , hubo intérpretes de música gallega de Buenos Aires que editaron placas en Galicia, por ejemplo el LP Festas galegas, un compilado de algunas regionales por Marfer en Madrid en ca. $1970^{2}$.

4. Autores gallegos con temática ajena a la gallega. Numerosos gallegos compusieron en géneros foráneos de Galicia, tanto en letra como en música. Entre ellos destaco las incursiones en el tango de Víctor Soliño, Eduardo Calvo Souto y José Vázquez Vigo $\mathrm{y}$, en el folclore argentino, Ramón Suárez Pérez.

5. Música de otros autores con temática vinculada a Galicia. Como un proceso espejado de la variante 4 , en el contexto del fuerte interaccionismo social que significa para un colectivo emigrante vivir en otra tierra, no fueron pocos los compositores de otras latitudes que incursionaron en la música gallega. Ejemplos son el catalán Alfredo Gatell Flemer, los navarros José Hernández y Daniel Cauvilla Prim, el valenciano Francisco Balaguer y los argentinos Horacio Pettorossi, Mario Canaro, Enrique Maciel y Horacio Guarany. En el ámbito de la música académica argentina hay obras compuestas por compositores como Isidro Maiztegui, Elsa Calcagno y Roberto Caamaño.

6. Intérpretes gallegos de música no vinculada a Galicia. Hubo gallegos que interpretaron géneros no gallegos como Dopazo, quien grabó obras asturianas y españolas en general, el cantor de tango vigués Antonio Rodríguez Lesende que grabó, entre otras, con las orquestas de Carlos Di Sarli y Stampone-Federico, y Francisco Cao Vázquez, conocido artísticamente como Panchito Cao, porteño hijo de orensanos quien por décadas se lo conoció como "el Gaitero de Texas (The Texas Piper)", pues así figura en el primer disco de lo que luego se convino en llamar música "celta", editado en Buenos Aires entre 1959 y 1960 (Cirio 1999, 2013).

2 Estas regionales no existieron como tales más que en el estudio de grabación. Véase más adelante mi explicación al dar cuenta del sello Hermifono. 
7. Varios. Incluyo en esta variante las grabaciones que no encuadran en las demás pero es pertinente considerarlas, como el recitado del poema Domingo Ferreiro del argentino Raúl González Tuñón (1952) en un LP en 1967. Esto se debe a que, con el tiempo, propició rumbas y muiñeiras tradicionales y el guarasón homónimo de Adolfo Castro y Eduardo Ríspoli (1949) grabado dos veces, ambas en discos de 78 rpm: una en Odeón por Osvaldo Norton y su Conjunto de Jazz y la otra en Victor por el Conjunto Cotton Pikers.

La etnomusicóloga colombiana Ana María Ochoa en su libro Músicas locales en tiempos de globalización (2003) aborda, entre otros aspectos, la posición dominante de las Majors en el circuito comercial de las músicas del mundo en lo que se llama, valga la redundancia, Word Music. Me interesa su reflexión sobre cómo, a fines del siglo XX, se ha incrementado notablemente la industria musical del llamado "repertorio doméstico", según la estadística del IFPI (International Federation of the Phonographic Industry). El término "repertorio doméstico" se aplica, desde esta perspectiva, a las grabaciones que sólo cubren el territorio nacional del país que las producen. Más amplio es el "repertorio regional" (para áreas mayores, como la música popular en español para América Latina) y, ya de alcance planetario, el "repertorio internacional". Llevada esta tripartición a mi estudio de caso, aunque no dispongo de cifras cuantitativas respecto, por ejemplo, a tiradas y circulación, cualitativamente puedo afirmar que mayormente se encuadra como "repertorio doméstico", siendo la excepción cierta circulación como "repertorio regional" que representan las variantes 2 y 3 descriptas, entendiendo por región al área gallego parlante que abarca Galicia y su colectividad en Buenos Aires. Aunque escapa a los límites de este artículo, señalo que la presencia de música gallega en la discografía de Word Music producida en la Argentina no pasa de ser excepcional y, en ningún caso, supera su circulación doméstica.

\section{Música gallega. La grabación como viven- cia social}

Quizá lo que haya venido incentivando a músicos y compositores a grabar música gallega o de esta temática no sea diferente a los intereses de la industria discográfica local en conjunto.
En Buenos Aires aún es una industria poderosa y prolífica, con un centenar de sellos que satisfacen las variadas ramas de la industria del entretenimiento, los actores sociales implicados fueron procurando atender intereses diversos pero no incongruentes entre sí: inmortalizar su nombre $y / o$ el de su agrupación, aquilatar su curriculum y ganar dinero, entre otras cuestiones. Como elemento adicional - pero no menor- está el fortalecer su sentido de pertenencia grupal o galleguidad, nervio sensible en el marco de la diáspora. Habiendo fundamentado la centralidad del quehacer musical entre los gallegos del país como fuente primaria para expresar y mantener su diferencialidad identitaria (Cirio 2006), se entiende por qué la industria vinculada a ellos cobró importancia, considerando al archivo generado, aunque de naturaleza incompleto, es representativo.

Aún desconocemos mucho sobre los mecanismos que posibilitaron la grabación de esta música pero cabe diferenciar entre las placas editadas por sellos del mercado internacional con filiales locales, como Odeón, Victor y Columbia -por citar tres de los más importantes-, y por emprendimientos autogestados. En el primer caso la variedad temática que la industria del entretenimiento, novedosa y floreciente hasta bien entrado el siglo $\mathrm{XX}$, requería que los sellos aquilaten su catálogo con una variedad de repertorio, instrumentos e intérpretes lo más frondosa posible a fin de posicionarse favoritos del público. Así, géneros como el alalá y la muiñeira convivían con la ópera (generalmente con trozos de obras), el tango, el bolero y el fox trot. Sin embargo, no fue hasta el inicio de las grabaciones en CD que los grupos gallegos locales comenzaron a incluir géneros hasta entonces desestimados de tradicionalidad (enxebrismo) en la cultura gallega como la rumba, el tango, el fox trot y la mazurca. Ello fue consecuencia de un viraje paradigmático de la concepción del folclore más amplia y dinámica de la que venía siendo dominante en Galicia, de cuño romántico anglosajón. En esa lógica los investigadores dejaban en evidencia sus pruritos hacia la modernidad al ponderar los géneros vigentes en el pueblo según su arraigo y antigüedad (Wade 2000). Este aspecto fue estudiado por el musicólogo gallego Luis Costa Vázquez respecto a "las rumbas olvidadas" en el Coloquio Internacional del ICTM, en 1999 (2004). En un artículo del 2001 también abordó la cuestión para atender la relación entre música y galleguismo en el 
marco de la construcción de la etnicidad y el nacionalismo. Desde su perspectiva -que comparto- tal apertura se vincula a dos consecuencias del temprano carácter restrictivo del estatus de galleguidad en el discurso etnicitario del galleguismo, tal como lo ideó Manuel Murguía y con su pronta consolidación como narrativa dominante. La primera es la agudización del proceso de folclorización al que se venía sometiendo un reducido corpus de música de tradición oral (la que él consideraba antigua, propia de Galicia, como los citados géneros alalá y muiñeira). La segunda es que, con el tiempo, esa restricción generó una tensión entre el discurso regionalista y los movimientos vanguardistas que proponían una relectura de la galleguidad que conecte la ancestral ruralidad con la cada vez más creciente vida citadina y -agrego yo-su nada despreciable representatividad en países como la Argentina. En esta perspectiva una lectura diacrónica de los géneros empleados en la discografía analizada da cuenta tanto de los "nuevos" géneros gallegos como de los caídos en desuso menos por la demanda del público que por ya no tener una plataforma ideológica que los sustente. Así, los prolíficos "cantos de pandeiro" en los discos de corales de mediados del siglo XX tenían su razón de ser en que ese era uno de los géneros rotulados por Murguía como tradicional, mas la ambigüedad de su definición no incidía en su aceptación por los lectores e investigadores posteriores dado el halo de incuestionabilidad con que él se impuso en el medio intelectual (Costa Vázquez 2001: 269). Es probable que esta apertura discográfica local haya sido consecuencia de la apertura de muchos grupos enxebres de Galicia. Cabe, para el futuro, trazar su estudio relacional y tómese como ejemplo la primera placa del grupo vigués Xistra da Coruxo que ya desde su título, Se beillas arrente coidado cos terróns (1995), indica su interés por géneros de pareja enlazada y que se bailaban sin saltos, hasta entonces despreciados por los enxebristas -intelectuales, en general, y musicólogos, en particular- como el tango, la polca y el samba, pero no por los músicos populares y sus respectivos públicos desde mucho antes como atestiguan, en el caso de la Argentina, los repertorios de las regionales (charangas) más antiguas que documenté, de principios del siglo XX. Prueba de esta (re)aceptación en el corpus estudiado es, por ejemplo, el grupo autodenominado de "folk gallego y asturiano" Os Furafoles. Su
CD FRFLS (2011) tiene la Rumba de Avelino (banda 3), que, según el folleto:

Aprendimos este tema de Avelino Rodríguez Arteaga, importante gaitero gallego de la emigración en Buenos Aires, quien formó parte del famoso grupo 'Los Monfortinos'. Originalmente era interpretada con formación de charanga como pudimos escuchar en una grabación de Avelino en los años 60.

\subsection{Las discográficas gallegas}

Hasta hace poco la posibilidad de grabar música comercialmente estaba restringida porque la tecnología, por su costo y conocimiento para manejarla, no solía estar al alcance de músicos y compositores. Una modalidad para acceder al mercado por quienes no eran convocados por las discográficas era pagarles para una grabación personal por cierta cantidad de placas, generalmente exigua, para obsequiar a amigos y/o como recuerdo familiar. En el caso de los discos de $78 \mathrm{rpm}$, si bien cada sello tenía su código de color para diferenciar repertorios -azul para clásico, verde para popular, etc.-, en todos la etiqueta blanca y el comienzo de la matriz con una $\mathrm{P}$ identificaba las grabaciones particulares las cuales, a la sazón, no integraban los catálogos del sello en cuestión. En esta modalidad grabó en RCA Victor el Conjunto Folklórico Español Los Cantábricos y Ángel Feito y su Conjunto a mediados del siglo XX.

Otra manera de grabar comercialmente que idearon los gallegos fue crear sus propios sellos. He documentado seis -dos de ellos en actividad (los $\mathrm{N}^{\mathrm{o}} 2$ y 6) entre 1940 y 2015. Aunque, de momento, la información conocida es despareja, doy su panorama cronológico.

1. Celta. Poco se sabe de este sello que funcionó en los 40. Grababa en la tecnología del momento, discos de $78 \mathrm{rpm}$ y sólo documenté seis placas, todas de gran calidad pues tienen obras interpretadas por gaiteros de la talla de Manuel Dopazo y cantantes líricos como los tenores José Vales y Domingo Caamaño (Cirio 2005a).

2. Ediciones Musicales Galicia / Ediciones Galicia. Empleando una u otra denominación según las épocas, el Centro Gallego viene editando placas desde 1958, siendo los últimos los CD Morriña en Buenos Aires (1999) y $O$ gozo de cantar galego -ambos de la casa- dirigido por Gabriel Lage (ca. 2014). La serie más famosa de ese sello la 
integran siete placas (seis LP y un simple, todos en $33^{1 / 3} \mathrm{rpm}$ ) con música académica grabada en vivo en teatros porteños durante las Xornadas Patrióticas Galegas, composiciones de Andrés Gaos como la sinfonía En las montañas de Galicia por la Orquesta Sinfónica de LRA, dirigida por Washington Castro, y coros gallegos. Al parecer, este sello se inauguró con 4 discos de $78 \mathrm{rpm}$ del Coro Residentes de Vigo dirigido por Julio Anta (1958).

3. Grabadora Regional Española Argentina. Pertenecía al grupo de acordeones Los Hermanos Moreira y funcionaba en el subsuelo de la peluquería que atendían, en el centro porteño. Sólo editaron dos simples de $33 \frac{1}{3} \mathrm{rpm}$ en 1963 y 1967 de su propio grupo, aunque cabe consignar que el segundo es un acople, pues en la cara B está la regional Celestino Paz y su Conjunto de Gaitas (Cirio 2009).

4. Hermifono. Propiedad de Amando Hermida Luaces e Alfredo Gatell Flemer, dos emigrantes españoles de Lebosende (Orense) y Tarragona, respectivamente, que estuvo en actividad de 1962 hasta ca. 1980. Fue parte de una empresa más amplia, pues como Hermifilm grabaron películas en el país y en Galicia. El estudio funcionaba en la casa de Hermida, en Valentín Alsina (Pdo. Lanús, Buenos Aires) y fue el más organizado y prolífico de los sellos gallegos, contando con un catálogo para los distribuidores mayoristas y comerciantes con sesenta títulos numerados correlativamente del $001 \mathrm{al}$ 060, precedidos por las sigla HF. Al menos hasta la placa 030 tenía sólo música gallega o española en general; desde la 031 a la 060 se advierte la búsqueda de un público más amplio, juvenil y popular, siendo lo gallego excepcional y predominando el repertorio español, el rock, el folclore paraguayo y la cumbia. Aunque la mayoría son discos simples y LP de $33 \frac{1}{3} \mathrm{rpm}$. Respecto a la música gallega predominan las regionales, aunque también está la Orquesta Española y el Coro Anaquiños de Casa de Galicia -ambas agrupaciones dirigidas por Gatelly tres grupos de Galicia: el Real Coro Toxos e Froles, la Agrupación Cántigas y Agarimos y la Banda La Lira, las que oportunamente enviaron sus másters grabados en España. Destaco una cuestionable estrategia pergeñada por Gatell en beneficio suyo y de su socio: salvo excepciones las obras interpretadas eran composiciones suyas o u obras tradicionales que, con un arreglo y nombre nuevo, las registraban como propias en SADAIC. Ello no sólo es posible advertir con un mínimo de conocimiento de la música gallega tradicional, él lo explicó en las varias entrevistas que le hice entre 2003 y 2005. De hecho, parte de las regionales que grababan allí no tenían entidad per se: estaban formadas ad hoc por ellos con nombres de fantasía que por una paga grababan un repertorio obligado. Siguiendo la memoria oral de Gatell $^{3}$ la clave para discriminar los grupos reales de los apócrifos está en las portadas: salvo excepciones sólo eran reales los que tenían por ilustración una fotografía del grupo, como Los Monfortinos (placas 001, 002 y 003) (Cirio 2005c), los apócrifos tenían paisajes gallegos, como -entre otrosLos Orensanos (placas 006 y 007, Los Estradenses (placa 008) y Los Ribadavienses (placas 014 y 016). Si aún en la Argentina las obras anónimas no tienen protección legal, la estrategia de muchos compositores de entonces era engrosar su catálogo y sus bolsillos echando mano sin mayor impunidad ni esfuerzo que lo que demanda un arreglo y el cambio de nombre ${ }^{4}$. Según Gatell -sin reconocerse parte del problema- "ellos firmaban los himnos, firmaban todo, firmaban todo, la Biblia también era de ellos, sí, primera y segunda serie, eh... Antiguo y

3 Fue de gran utilidad entrevistar a Gatell Flemer durante años. Cuando me contacté con Hermida, si bien estaba bien de salud y dispuesto a atenderme, al poco tiempo falleció y no llegué a conocerlo.

4 Aunque el plagio no se ha instalado en esta colectividad como modus operandi, cabe señalar un caso contemporáneo: las obras Rial adiante y Baila rapaza (bandas 1 y 2, respectivamente), del CD demo Andaína que el grupo A Deixa grabó en Buenos Aires en 2004, figuran como Baila, rapaza y Cantar de arrieiro (bandas 6 y 7, respectivamente) en el CD De Ruada en Bos Aires, del grupo A Curuxa, dirigido por Walter Almirón García y editado en Galicia en 2007 por Do Cumio (CD21185).

5 TC 152. Alfredo Gatell Flemer (78 años de edad), Buenos Aires, 4/11/2004. 
Nuevo Testamento, todo era de ellos. Entonces llegó un punto que le pararon el carro y entonces uno de ellos se asustó y dijo 'Bueno, señores, terminenlá porque ustedes se están metiendo en un lío de juicios que... terminemoslá" "5. Pese a esta sugestiva operatoria -reconocida por él pero practicada para extraer pingües beneficios- gracias a este sello contamos con registros de destacadas agrupaciones aunque, paradójicamente, como el repertorio grabado sólo era para este fin, no son representativos de sus actuaciones.

5. Centro Lucense de Buenos Aires. Subsumido en 1978 junto a los otros tres centros provinciales en el Centro Galicia, editó al menos tres LP (uno también en casete): uno con música académica gallega por la Banda Sinfónica Gallega del Centro Lucense de Buenos Aires, dirigida por José Pazos (ca. 1958); Galiza, onte, hoxe e sempre de la Coral Os Rumorosos del Centro Betanzos de Buenos Aires, dirigida por Carlos López García (1971); y Cantares gallegos, de Graciela Pereira con el acompañamiento de Casino Show, dirigida por Manuel Fuentes (ca. 1980).

6. Centro Galicia de Buenos Aires. Resultante de la fusión de los cuatro centros provinciales en 1978, esta entidad es desde entonces la más fuerte de las asociaciones gallegas del país. Entre sus emprendimientos está la publicación de tres placas: el casete Música celta del Conjunto de Música Celta del Centro Galicia de Buenos Aires (ca. 1990); el CD Ábrego del Conjunto de Música Folk del Centro Galicia de Buenos Aires, dirigido por Gustavo Fontana (1996); $\mathrm{y}$, del mismo grupo, el CD Áncora briga (2004).

\subsection{Galicia-Buenos Aires-Galicia}

Una particularidad de la generación del corpus estudiado es la cantidad de grabaciones que, realizadas en Galicia, se editaron en Buenos Aires y viceversa ${ }^{6}$. La práctica se remonta al menos a 1928, cuando Manuel Quiroga (violín) y Marta Leman (piano), grabaron por RCA Victor cuatro obras en dos discos de 78 rpm, tres de Quiroga y una anónima arreglada por él (Martínez Blanes 2004). Quizá esta estrategia estuvo condicionada por las elementales condiciones de la industria discográfica gallega, encontrando en Buenos Aires un óptimo mercado donde vender las placas, formado básicamente por inmigrantes gallegos pero también españoles en general y argentinos cultores de la música académica. Además de las placas referidas de conjuntos gallegos que editó Hermifono, en 1970 Ediciones Galicia publicó como el Vol. 2 de su serie de siete discos uno de la Coral Polifónica de Porriño, dirigido por Paz Valverde, síntesis de tres discos simples editados en España. Su contratapa da cuenta de ello:

\section{Círculo Recreativo Cultural de Porriño}

Carta del 5/10/70 dirigida a la Sociedad Residentes del Municipio de Porriño en Buenos Aires.

...nos complacemos en comunicarles que la Junta Directiva de esta Sociedad, en sesión celebrada el día 21 de setiembre ppdo., muy gustosamente ha acordado autorizarles la grabación en un 'long-play' de las canciones que nuestra Coral Polifónica tiene grabadas en 3 discos 'Canzón Galega'.

Igualmente y por medio de la presente, el director de la Polifónica, D. Antonio Ignacio Paz Valverde da consentimiento para dicha grabación.

\section{Las conformaciones musicales en per- spectiva diacrónica}

A lo largo del tiempo los gallegos -emigrados o no- han ido cambiando las significaciones estéticas de la música que producen y consumen, entre ellas la cuestión no menor de su relevancia social y representatividad étnica. Esto se concatena con la posibilidad de reconocerla como propia (Martí i Pérez 1995, 1996) y es proceso en el cual la fonografía ha venido siendo arte y parte. Desde el punto de vista diacrónico advierto en el corpus reunido

Como aquí me centro en lo editado en esta ciudad dejo para otro trabajo la música que, siendo grabada en aquí, se publicó en Galicia. 
que, durante ciertos períodos, la manera de hacer música -lo que incluye su grabaciónestuvo dominada por ciertas agrupaciones, pudiendo reaparecer en otra generación. Daré dos ejemplos. Del orfeón -agrupación coral masculina numerosa en Europa y América en el contexto del requerimiento de solaz para las masas obreras en pleno proceso de disciplinamiento laboral (Costa Vázquez 1998) y que en la Argentina fue de aprecio por el español (Varela Lenzano 1904)- apenas hay datos de los once orfeones gallegos activos en Buenos Aires entre 1890 y 1925, quizá porque la industria discográfica apenas había comenzado y por la dificultad tecnológica para grabar masas con calidad. Ello explicaría por qué se conocen sólo dos discos de 78 rpm del Orfeón Gallego de Buenos Aires, dirigido por Francisco Rivara en el sello Atlanta, uno de 1912 y el otro de 1914. Aunque en esta colectividad, como en Galicia, la gaita tiene un estatus de alta relevancia en tanto es portadora, por excelencia, de los más altos significados que implica la galleguidad (Costa Vázquez 2001: 259), si allí como aquí hay una práctica extendida en tanto, virtualmente, todo miembro puede practicarla -al menos como solaz en una reunión familiar o pública- es el canto con pandeireta. Sin embargo, a no ser por alguna pandeiretada de corales a mediados de los 50 , fue hace poco que se formaron algunos grupos que practican este género de manera central en su repertorio (como A Deixa), pero al momento de la redacción de este artículo no han grabado placas.

Otros tipos de agrupaciones vocales, como los coros y las polifónicas (que, a diferencia del orfeón, eran mixtos), tuvieron su esplendor en las décadas del 40 al 60 y su correlato en abundantes placas por la mayoría. Se destaca el lujoso álbum de cinco discos de $78 \mathrm{rpm}$ de 30 $\mathrm{cm}$ de la Coral Gallega Terra Nosa del Centro Orensano de Buenos Aires, dirigida por Isidro Maiztegui y que grabó de modo particular en RCA Victor (1952), reeditado luego en LP como el $N^{\circ} 1$ de la serie de discos de Ediciones Galicia (1970). También grabaron el Coro Airiños de Vigo, dirigido por Antonio Maceira (dos discos de $78 \mathrm{rpm}, 1955$ ), el Coro Arrieiros da Peña Xuvenil de Cultura d'Asociación Residentes de Mos (un disco de 78 rpm, 1961) y el LP Galiza, onte, hoxe e sempre de la Coral Os Rumorosos del Centro Betanzos de Buenos Aires, dirigida por Carlos López García (1971). A partir de los 80 la coralística bajó en cantidad (de agrupaciones y de miembros por agrupación) y calidad. Hoy son pocas las corales existentes y es aunado el criterio de sus performers y del público de que, aunque con entusiasmo y esfuerzo, su musicalidad no es la de antaño. De la producción reciente están los referidos CDs. del Coro del Centro Gallego. Cabe destacar que de su época de oro el Coro Castelao da Sociedade Parroquias Unidas del Ayuntamiento de Rianjo, dirigido por Ángel Romero, editó en 1948 un disco de 78 rpm por RCA Victor con dos obras, siendo una el vals Ondiñas da nosa ría (música de Ángel Romero, letra de Jesús Frieiro), conocida como $A$ rianxeira y devenida prontamente en uno de los máximos índices de galleguidad (Cirio 2003).

Las obras con gaita en diferentes conformaciones -solista, con canto, en regional, en grupo tradicional, en banda, acompañando a coros, en música "celta", etc.- son un elemento omnipresente y central en este corpus. Hay desde eximios gaiteros hasta otros de rudimentaria calidad, afinación y trascendencia. En el caso de los discos de $78 \mathrm{rpm}$, como casi toda la información consignada sólo iba en las etiquetas circulares pegadas al centro, no siempre satisfacen todas las cuestiones documentales, tal es así que sorprende cómo no pocas veces se prescinde del intérprete. En mi CD sobre Manuel Dopazo (Cirio 2005a) incluí varios de estos registros tras un minucioso análisis de su estilo interpretativo y comparándolos con grabaciones en las expresamente dice que son suyas. Así, incluí el disco de Atlanta con $\mathrm{Mu}$ neira (cara A) y la polca Raquel (cara B) $\left(\mathrm{N}^{\circ}\right.$ 744, matrices 65564 y 65566), que sólo dice "Gaita sola y tambor" y "Dulzaina, gaita con acompañamiento", respectivamente. Además de su inigualable performance, creó la primera banda de gaitas que se tenga noticia, Los Gaiteros de Vilaverde, representando una innovación para la música tradicional y desfilando con su marcha, Los Gaiteros de Vila Verde (Manuel Dopazo y José Barreiro 1942). Aunque aún no se conoce ninguna grabación de ella más que una breve intervención en una película argentina, la discografía de Dopazo está incompleta, por lo que quizá haya grabado con su banda (Cirio 2005a 2014). Más allá de este temprano y excepcional caso, a finales de los 90 la banda de gaitas resurgió como agrupamiento tendiendo, por ejemplo, la de Emigrantes Gallegos, dos CDs. de producción independiente (2005 y 2007). 
Sobre la denominada música "celta" -etiqueta comercial interatlántica solícita con el topos murgiano del celtismo, piedra basal de su relato historiográfico sobre el origen de la cultura gallega (Costa Vázquez 2001)-, excepto por el citado disco de "el Gaitero de Texas" (1959-1960) como lejano y excepcional antecedente, comenzó con el grupo Poitín cuando en 1988 grabó un casete de manera particular. Contemporáneo a él, Xeito Novo (luego Fundación Xeito Novo de Cultura Gallega) surgió como una escisión izquierdista del Cuerpo de Baile "César Quiroga", del Centro Betanzos. Si bien al comienzo no se definió como celta7, luego devino en un prestigioso grupo autodenominado de "folk celta" y es el más antiguo en actividad del país, contando con cinco placas: Xeito Novo -primero en LP y casete, luego en CD- (1987), Galimerica (1994), Compostelae (1997), Luz de invierno (2000) y Xanelas (2005). Otros grupos de música celta de extracción gallega que editaron placas son Potim y Sete Netos, además de los referidos Ábrego y el Conjunto de Música Folk-Celta del Centro Galicia de Buenos Aires (Cirio 2011a).

La composición de música académica por gallegos en Buenos Aires es más abundante de la que se ha grabado. Ello se debe a la dificultad de satisfacer los requerimientos técnicos, el conocimiento para su ejecución y dirección, así como el costo para su grabación. Si a ello sumamos que está destinada a un público que, por selecto no es masivo, se comprende por qué en esta discografía hay pocos registros. Como sucedió con la música académica argentina en general, ninguno data de la época de la grabación acústica (García Muñoz, Goyena y Vigo 1999) porque, como explica Timothy Day (2000: 18-19) para el mercado discográfico mundial, lo incipiente de la industria fonográfica debía priorizar la popular a fin de ser rentable ${ }^{8}$. De lo grabado destaco los LP Xornadas Patrióticas Galegas (ca. 1974) y Composiciones de Andrés Gaos (ca. 1975), ambos de Ediciones Galicia, además del citado de la Banda Sinfónica Gallega del Centro Lucense de Buenos Aires. Entre los 83 másters documentados que no llegaron a comercializarse hay un disco de $331 / 3 \mathrm{rpm}$ de acetato de $20 \mathrm{~cm}$ del Trío Galicia - dúo vocal femenino y piano- grabado en Estudios Peña (ca. 1940) con cuatro obras, entre ellas un arreglo de Fernández Espinosa del romance anónimo Camiña don Sancho. Además de tratarse de un arreglo en la estética de la música académica, el registro es excepcional. El romance es un género que no ha venido siendo de interés en el corpus analizado. Ello fue menos por el gusto del público-Galicia territorial y su colectividad en la Argentina tiene una interesante tradición romancística (Valenciano 1998, Cirio 2007)que por ser obras que solían exceder la duración estándar de cuatro minutos de las grabaciones, duración que, lejos de ser natural, fue moldeada por la misma industria discográfica (Day 2000).

\section{Conclusiones}

El corpus analizado presenta particularidades que dificultan su estudio sistemático. Desarrollo seis, entre otras posibles:

1. Atomización. La compilación de esta discografía -sean las placas originales o copias- es el primer escollo. No existe en el país un repositorio público que las reúna y se las pueda consultar, aunque se pueden encontrar algunas en entidades gallegas, institutos de musicología y la Biblioteca Nacional, así como en colecciones privadas. La manera en que he ido reuniendo el corpus presentado es asaz asistemática, lo que incluye la compra en el mercado de antigüedades a precios variables. Urge la necesidad de sistematizar este corpus en una publicación, como ser un catálogo razonado, proyecto que planifiqué hace unos años mas aún no hallo medios para concretarlo (Cirio 2005d).

2. Representatividad. Que haya placas de un grupo no implica que haya existido, como los no pocos inventados por Hermifono. Por otra parte, y según la bases de

7 De hecho, con Xeito Novo, su primera placa, editada en Galicia (su estudio no concierne a este artículo) en 1987 por Edigal, el grupo sólo cubría parcialmente tal expectativa.

8 Incluso Thomas Alva Edison tenía en 1923 una opinión negativa sobre el público de su producto, desestimándolo como "muy primitivo" dada su inclinación a la música popular, en detrimento de la "más avanzada" (Day 2000: $65)$. 
datos propia, existieron en la Argentina 288 conjuntos y solistas gallegos de los cuales grabaron 86 (menos de un tercio), al menos una placa.

3. Fragilidad. No todos los soportes tienen la igual capacidad para perdurar en el tiempo de manera óptima para su reproducción. Aunque de momento no hallé cilindros con música gallega, al ser de cera su fragilidad es comparable a la de los discos de $78 \mathrm{rpm}$, la mayoría de los cuales datan de los años 40. En los discos de acetato es usual que la laca que contiene la música se aje, lo que implica la pérdida irreparable de los surcos, impidiendo su reproducción. Similar deterioro tiene el casete porque la cinta, por características intrínsecas, con el tiempo se pone gomosa, lo que ralenta o impide, su circulación. En base a mi experiencia recomiendo la menor exposición posible de las placas a su reproducción: debe procurarse una buena y única reproducción para su digitalización y, de ahí en más, sólo valerse de ésta que, de hecho, puede mejorarse sustantivamente dados los sofisticados softwares existentes. Un disco rajado, rayado e, incluso roto no es inservible, pues contando con dos iguales puede reemplazarse digitalmente la parte dañada con la sana del otro9.

4. Capacidad de reproducción. Todo soporte con música grabada debe ser puesto en un reproductor para acceder a su contenido. Hoy el usuario promedio no tiene ni maneja más que con las dos últimas tecnologías: los lectores de CD y las caseteras, cuando no sólo la última. Para los soportes anteriores deben tenerse los aparatos específicos cuyos costos y conocimientos para su manejo implica una considerable inversión de tiempo y dinero: bandeja de discos con graduación de rpm y diferentes tipos de púas, pianolas y fonógrafos para los cilindros, ambos últimos joyas de coleccionistas de alto costo. Con todo, siguiendo a Timothy Tylor (2001), el almacenamiento digital marca una diferencia básica respecto a los que le preceden ya que, por sus características, no requiere soporte físico ni para su almacenaje ni para su transmisión, entrando así a la era que Steven Feld (2000) denomina "sonoridad virtual".

5. Unicidad. Usualmente la tirada de una placa, para que sea redituable y satisfaga al mercado, es de miles de copias aunque no de pocas, sobre todo las más antiguas, sólo se editaban unas pocas o algunos cientos. En las que promedian ya un siglo de antigüedad, si ponderamos los problemas que debieron sortear para llegar al presente en condiciones de ser reproducidas las posibilidades de hallarlas son pocas, y no hablo sólo de accidentes: durante la Segunda Guerra Mundial la escasez de goma laca para la industria discográfica -y otras, como la del peine- motivaron a los botelleros a comprar discos de pasta para su fundición, generándose la destrucción de mucho de lo editado ${ }^{10}$.

6. Integrar el corpus en un todo coherente. Las placas son el centro de estudio aquí pero no un fin en sí mismo. Es imprescindible disponer con otras fuentes para generar datos diagnósticos y poder contextualizarlas, lo que incluye la teoría de la recepción. Después de todo, el objetivo primero de las grabaciones es ser escuchadas $\mathrm{y}$, si bien hasta mediados del siglo XX muchos compositores e intérpretes académicos de las metrópolis seguían siendo escépticos de esta industria (Day 2008: 26, $49,231)$, el viso de inmortalidad que le daba al performer eliminaba la hasta hacía poco infranqueable característica efímera de la música. Un aspecto a contemplar en el uso de las grabaciones es el dado por los organizadores de fiestas de la colectividad. No sólo eran más redituables al ahorrarse el pago a los músicos, el darles de comer y sortear vicisitudes como la puja por mejores contratos o negarse a tocar más de lo estipulado sin renegociar la paga. Deleitar al público con discos era un modo sofisticado de mostrarse modernos. Así, el Centro Orensano de Buenos Aires en su periódico El Orensano (10/2/1945, p. 4) publicitaba

9 Así procedí con la banda 5 de mi CD de Manuel Dopazo (Cirio 2005a).

10 Héctor Lucci, comunicación personal. 
sus fiestas de carnaval con el ancestral rito del enterro da sardiña, desfile de máscaras infantiles y el baile dos paragüeros (sic), especificando que "Como todos los años, se bailará en el salón de actos y en las pistas al aire libre y serán encargados de su amenización un conjunto de gaitas y las mejores orquestas del momento en selectas grabaciones" $"$. Hoy esta situación tiene plena vigencia y es fácilmente detectable a nivel etnográfico, lo que invita a estudiar el consumo de grabaciones desde la performance. Por dar un ejemplo, promediando la primera entrada de la regional Los Lucenses en una fiesta del Centro ABC del Partido de Corcubión (Vicente López, Buenos Aires) el 1/5/2001, el locutor que, a la sazón, era el sonidista y tenía su equipo adelante del escenario, dijo: "La Orquesta Los Lucenses una sola pieza más continúa, un pasodoble, y después sí, sí gustan de la música, le seguiremos pasando ahí, por el $\mathrm{CD}$, la música moderna, tango, y lo que ustedes me pidan, eh, hoy vine preparado para la guerra, eh. Los Lucenses, entonces ahora aprovechan el locutor y dicen que les anuncie [el pasodoble] Noche torera".

Entre los aspectos no menores para lograr un todo coherente está la datación de las grabaciones. En los discos de $78 \mathrm{rpm}$, casi nunca figura en la escasa información que tienen ${ }^{12}$ y es una falencia que, inexplicablemente, se extiende a casi todos los soportes posteriores, incluso en CD. Así, sin asirse de los no menos escasos y costosos catálogos de las discográficas y de las casas de música, poco podemos hacer para precisar cuándo se hicieron. Dar con los actores implicados (músicos, compositores, productores, etc.) permitirá, vía la etnografía y los documentos que conservan, acceder a la "cocina" de su existencia. El caso de los grupos apócrifos de Hermifono -que un estudio detenido podría encuadrar dentro del concepto de piratería discográfica tal como lo trata Ochoa (2003: 77-82)- puede ser excepcional pero, de no haber sido por las entrevistas que hice a Gatell, aún estaría buscando, infructuoso, notas periodísticas y fotografías de ellos, lamentándome de su tenaz ausencia. Otras fuentes usualmente no consideradas por nimias, como las tarjetas de presentación de los conjuntos, revelan sugestivos matices para un análisis exhaustivo de esta faceta de la migración gallega (Cirio 2011b).

Las seis particularidades detalladas sobre la dificultad del estudio sistemático de esta discografía son extrapolables, con matices, a la música de la Galicia territorial, aunque allí hay repositorios oficiales que la albergan, como el Consello da Cultura Galega y el Museo de Pontevedra. Esta discografía también comienza a ser estudiada, sea confeccionando catálogos (Comesaña Martínez 1999) o realizado estudios acotados a temáticas y períodos (Estévez Vila 2007) en consonancia con proyectos similares de España en general (Biblioteca Nacional 1988), Italia (Leydi 1989) y la Argentina (García Muñoz, Goyena y Vigo 1999; Elías 2015).

Xosé Manoel Núñez Siexas en su libro $O$ inmigrante imaxinario (2002) aborda los estereotipos, representaciones e identidades de los gallegos en la Argentina en el período 18801940. Como buena parte de ese período coincide con el analizado aquí, es pertinente tomar su libro como referente pues, además, le dedica un capítulo, el V (pp. 245-319), a las fiestas étnicas como crisol de identidad, algo inusual en los historiadores y que, por cierto, resuelve bien al combinar métodos cuantitativos y cualitativos. Aunque resulta imposible atender su abordaje en el corto espacio de este artículo, de cara a mi tema de interés aquí señalo tres cuestiones: 1) entender las fiestas de esta colectividad como una combinación ecléctica de materiales musicales, literarios, teatrales y simbólicos argentinos, españoles -en generaly gallegos -en particular-; 2) existieron varios momentos y etapas en estas fiestas, por ejemplo hasta 1905 corrieron a cargo del Centro Gallego y dos orfeones y eran de clara orientación elitista. De sus programas publicados en la prensa gallega local se advierte que el peso de los referentes identitarios gallegos era bajo respecto a los españoles en general y la música clásica; 3) a partir de 1904-1906, al irrumpir

11 El resaltado es mío.

12 La excepción son los del sello TK. 
las sociedades de instrucción -de referencia peninsular microterritorial-, hubo una expansión de las fiestas gallegas, adoptando un cariz popular de gran rentabilidad en términos comunitarios ya que aumentó el espacio simbólico destinado a lo gallego, por ejemplo con bailes animados por grupos de música tradicional y la introducción, cada vez mayor, de obras de alto valor identitario, como la Alborada de Pascual Veiga. En estas fiestas también eran apreciadas músicas locales, como el tango, e internacionales, como el jazz, conservando lo referente a España en general aquello de índole popular, como el flamenco, los pasodobles toreros y piezas de zarzuela. Núñez Seixas aborda estas y otras cuestiones valiéndose de tablas cuantitativas confeccionadas por él. Veamos si este enfoque metodológico mixto es aplicable aquí.

Sintetizando información de archivo y etnográfica propia cifro la existencia de 289 grupos y solistas en el país desde 1878 (el más antiguo datado, la comparsa Inmigración gallega, de Buenos Aires) a 2015. Atendiendo a sus modos de expresión, comparo la cantidad que hubo de cada uno con aquellos que grabaron, obteniendo el siguiente cuadro formado por 17 tipos diferentes, más otro casillero para los minoritarios e indeterminados.
Los guarismos resultantes, absolutos y porcentuales, son difíciles de interpretar por sí mismos y pueden ocasionar malentendidos. Mientras sólo el 25\% del modo de expresión mayoritario, la regional, ha grabado, otros cuantitativamente menores, como el cuarteto y la banda de gaitas, con 10 y 9 formaciones respectivamente, tienen casi el $50 \%$ de representatividad. La exigua cantidad de orfeones que grabaron sobre los que existieron (1 sobre 11) puede indicar a menos tres cosas: 1) el desinterés de esa formación por la grabación; 2) la dificultad para obtener grabaciones de calidad (por el período en que existieron eran acústicas y deficitarias para grabar a masas corales con claridad); o 3) los discos documentados no son representativos de los existentes, cuya cifra se desconoce. Sobre el acordeón, al haber habido uno y tener grabaciones, el porcentual es del $100 \%$, lo cual vicia su representatividad. De la misma manera, pero a la inversa, los modos mejor representados son la orquesta académica, con el $80 \%$ y el solista, con el $63,15 \%$, pero la cantidad de intérpretes de ambos modos de expresión es pequeña.

Por lo expuesto descreo que el método cuantitativo, por sí, sea el mejor modo de evaluar la dinámica de esta industria discográfica pero, al menos, sirve tener una visión de

\begin{tabular}{|l|l|r|r|l|}
\hline $\mathbf{N}^{\mathbf{0}}$ & Modo de expresión & Cantidad & Grabó & $\mathbf{\%}$ \\
\hline 1 & Regional & 64 & 16 & $25 \%$ \\
\hline 2 & Conjunto tradicional & 59 & 14 & $23,73 \%$ \\
\hline 3 & Coro (corales y polifónicas) & 36 & 14 & $38,88 \%$ \\
\hline 4 & Orquesta popular & 28 & 9 & $32,14 \%$ \\
\hline 5 & Solista (canto, piano, acordeón, gaita) & 19 & 12 & $63,15 \%$ \\
\hline 6 & Orfeón & 11 & 1 & $9,09 \%$ \\
\hline 7 & Cuarteto de gaitas & 10 & 5 & $50 \%$ \\
\hline 8 & Rondalla & 9 & 4 & $44,44 \%$ \\
\hline 9 & Banda de gaitas & 8 & 3 & $37,50 \%$ \\
\hline 10 & Compańía & 6 & 1 & $16,66 \%$ \\
\hline 11 & Cantareiras & 6 & - & - \\
\hline 12 & Orquesta académica & 5 & 4 & $80 \%$ \\
\hline 13 & Banda de metal & 5 & - & - \\
\hline 14 & Dúo vocal & 3 & 1 & $33,33 \%$ \\
\hline 15 & Banda de jazz & 4 & - & - \\
\hline 16 & Escuela de gaitas & 2 & - & - \\
\hline 17 & Conjunto de acordeones & 1 & 1 & $100 \%$ \\
\hline 18 & Varios e indeterminados & 15 & 1 & $6,66 \%$ \\
\hline & TOTAL & $\mathbf{2 8 9}$ & $\mathbf{8 6}$ & $\mathbf{2 9 , 7 5 \%}$ \\
\hline
\end{tabular}


conjunto. Llegado a este cuello de botella propongo otro razonamiento. Dado el alto sentido gregario que manifiesta el gallego tanto en su tierra como en el extranjero, los diacríticos vinculados a las unidades geopolíticas natales - comenzando por el de Galicia hasta las de menor tamaño, como parroquias y aldeasaparecen con frecuencia dominante tanto como denominación de sus entidades sociales como en el nombre de sus grupos musicales. Asumiendo el riesgo de lo que implica simplificar a un esquema el derrotero de millones de gallegos y sus descendientes en el último siglo y medio en Buenos Ares, advierto como estrategia generalizada que el hacer musical con cierta profesionalidad es una actividad que organizan institucionalmente. En otras palabras, el gallego inmigrante buscó primero asociarse con sus pares, formando instituciones de carácter macro o microterritorial $\mathrm{y}$, así religado, procuró hacer música tomando para el nombre del grupo la unidad macro o microterritorial a la que adhiere, lo que da la siguiente lógica de acción: Inmigrante $\rightarrow$ entidad social gallega $\rightarrow$ conjunto gallego.

Así, es comprensible que la casi totalidad de los modos de expresión consignados funcionen e, incluso, pertenezcan a una entidad gallega, siendo la excepción -notable cuantitativamente, por cierto- las regionales. Si es el hondo sentimiento gregario el que lleva al gallego, motivado por la morriña, a asociarse con sus coterráneos recreando su unidad administrativa natal, y siendo éstas expresadas en la mayoría de los grupos musicales documentados $(52,42 \%)^{13}$, entonces puede inferirse el alto sentido que la música cumple en la cosmovisión gallega local, para lo cual propongo entenderla como territorio sonoro. Lejos de ser una característica de este grupo, "las grabaciones se han utilizado como íconos auditivos a los que un oyente puede volver una y otra vez durante muchos años (...), rodeando los sonidos inmutables de sus asociaciones y recuerdos personales siempre en desarrollo" (Day 2000: 211). En efecto, el territorio sonoro viene a constituir, en el imaginario de esta colectividad, el espacio de representación sénsoro-espacial de la Galicia dejada, activando la morriña mediante la galleguidad el necesitado anclaje de sentido de pertenencia para restablecer, lo más posible, el cuerpo social partido. La música como territorio sonoro funciona aquí, a un tiempo, como medio de expresión y constitución del ser gallego, de la galleguidad, tomando como denominador común el orgullo territorial total (Galicia) y/o sus divisiones administrativas (provincia, concejo, parroquia, aldea, etc.).

Excede al presente artículo abordar este concepto con el espacio y la fundamentación que requiere, por lo que lo dejaré para otro trabajo. Con todo, a modo de síntesis, puedo aplicarlo en la idea de que el grabar música viene siendo para los gallegos emigrados a Buenos Aires y sus descendientes -ya argentinos- una de las estrategias para vehiculizar sus sentimientos de pertenencia, procurando perdurar en el tiempo aquellos sones aprendidos y vividos en Galicia que ayudan a sentirse bien paliando la morriña que, cual negra sombra, parece asomarse al pie de sus cabezales por más que el éxito de una buena familia y un buen pasar sean motivo para alegrarse.

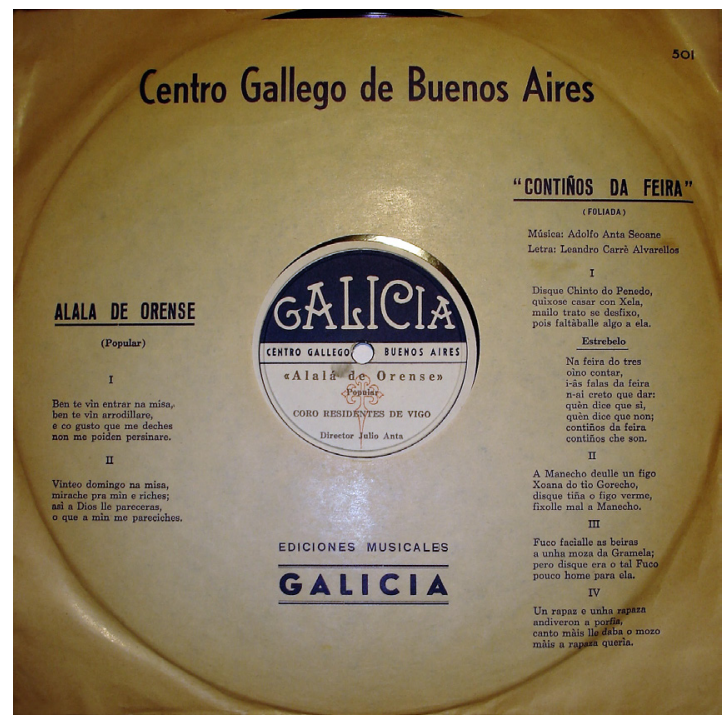

Las fundas de papel con que se vendían los discos de $78 \mathrm{rpm}$ eran ocasionalmente empleadas para brindar información, como este de Ediciones Galicia, del Centro Gallego de Buenos Aires (Col. Pablo Cirio)

13 Exceptúo a los 19 solistas documentados ya que se presentan sólo con su nombre. 


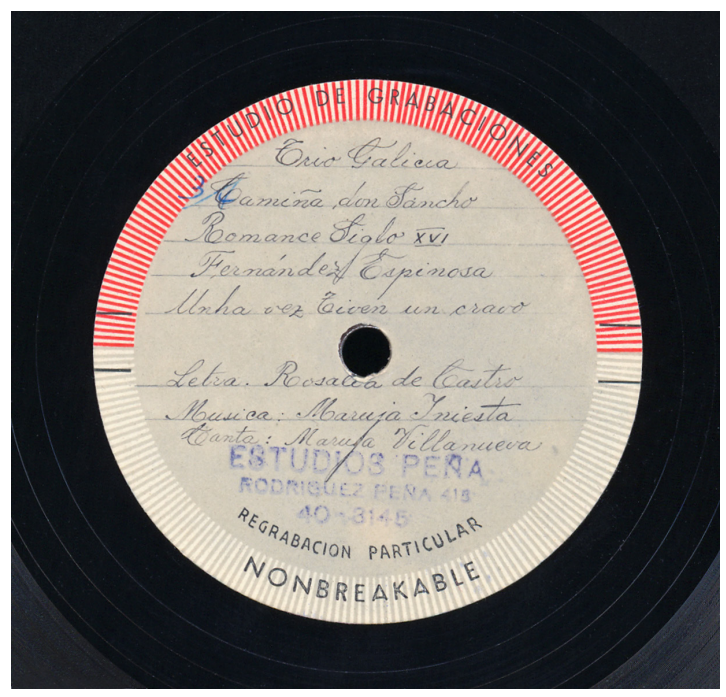

Disco inédito de acetato de $33^{1 / 3} \mathrm{rpm}$ del Trío Galicia (música académica). Buenos Aires, ca. 1950 (Col. Pablo Cirio)

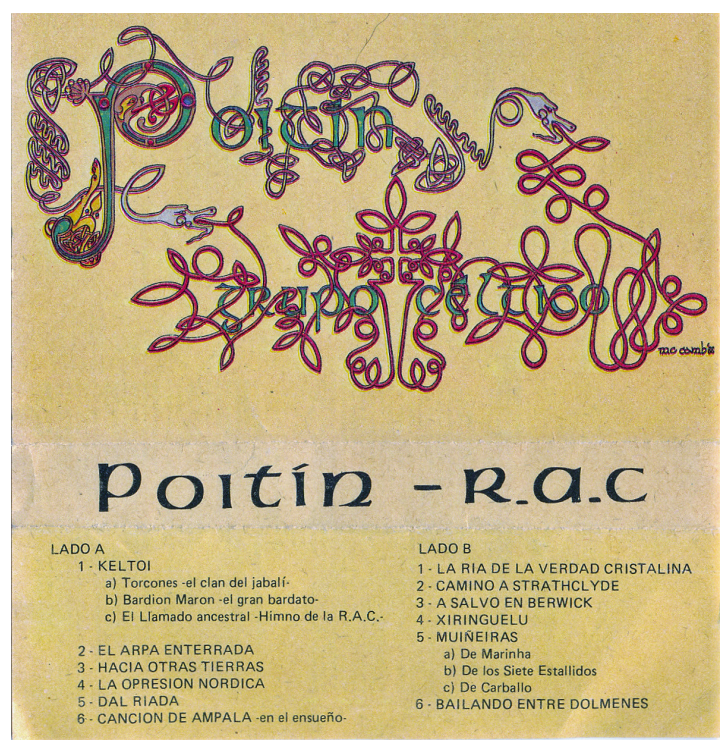

Primera grabación de música "celta" en la Argentina. Casete del grupo Poitín, edición particular. Buenos Aires, 1988 (Col. Pablo Cirio)

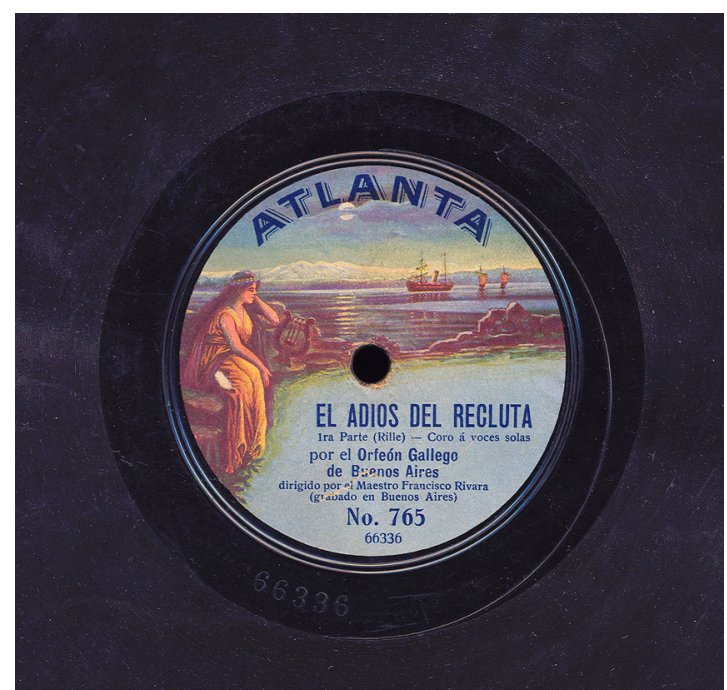

Disco de pasta de 78 rpm del Orfeón Ga-llego por el sello Atlanta. Buenos Aires, 1912 (Col. Pablo Cirio)

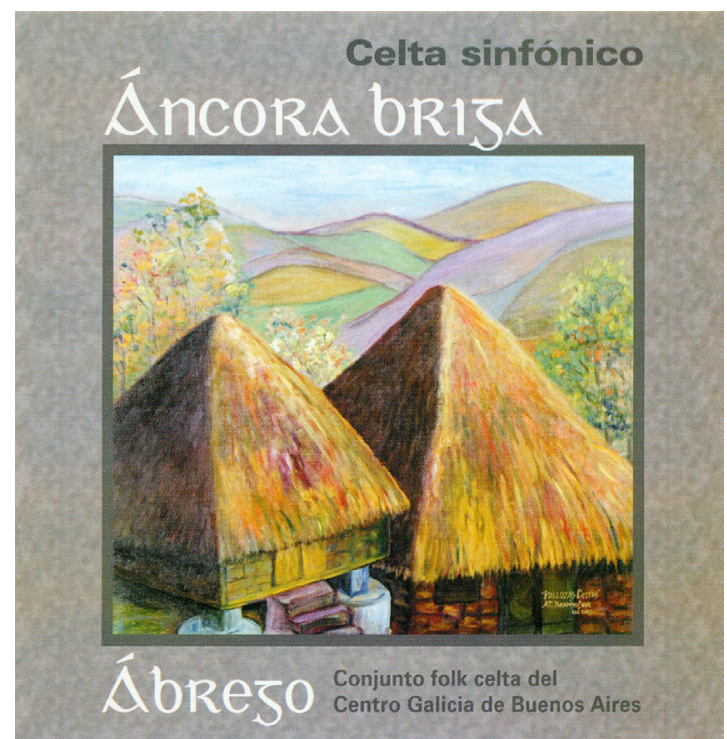

Portada del CD de Ábrego del Conjunto de Música Folk del Centro Galicia de Buenos Aires (Dir. Gustavo Fontana), editado por esa entidad, en 1996 (Col. Pablo Cirio) 


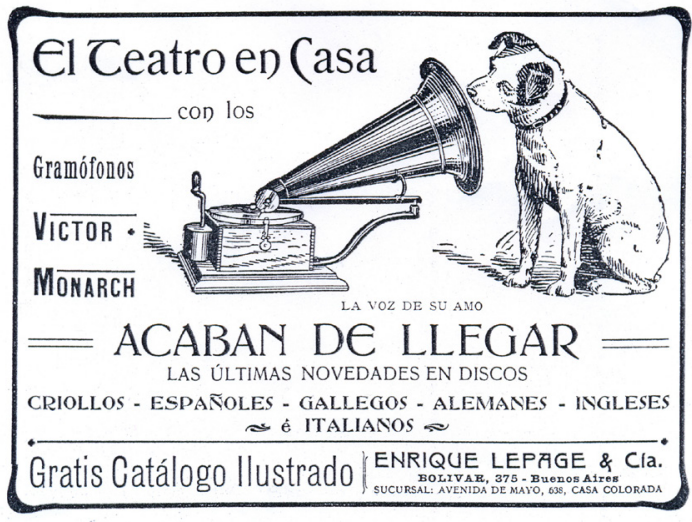

Propaganda de la discográfica Victor, en la que destaca, entre otros, discos de música gallega. Buenos Aires, ca. 1920

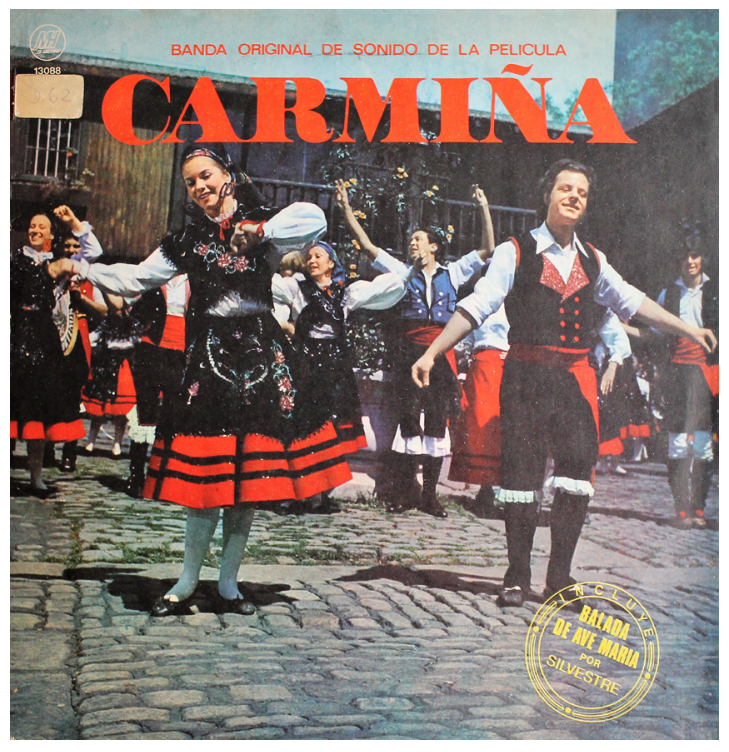

Portada del LP Carmiña (sello Music Hall), con la banda musical de la película argentina homónima en la que actuó la charanga Los Monfortinos. Buenos Aires, 1975. Curiosamente el disco no tiene los temas gallegos interpretados, aunque se valió de la escena en que toca la charanga para la portada (Col. Pablo Cirio)

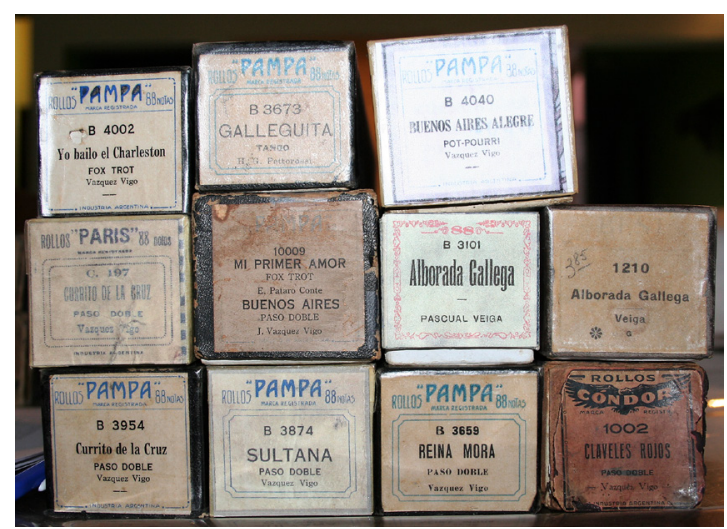

11 rollos de pianola con música gallega editados en Buenos Aires a principios del siglo XX (Col. Horacio Asborno)

\section{Conjunto de Acordeones Hnos. Moreira} y sus Vocalistas en Canciones Gallegas

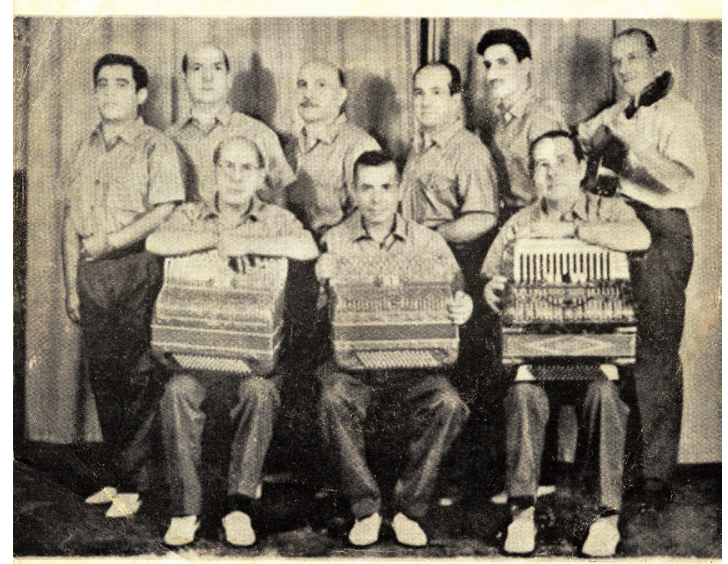

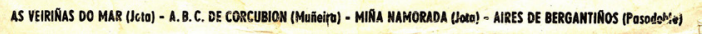

Frente del disco simple del Conjunto de Acordeones Hermanos Moreira grabado por la Grabadora Regional Española Argentina, de su propiedad. Buenos Aires, 1963 (Col. Pablo Cirio) 


\section{Referencias discográficas ${ }^{14}$}

Cirio, Norberto Pablo (2005a): Manuel Dopazo. Crónicas porteñas. Sarria: Ouvirmos VR0103. CD. (2005b): La música tradicional gallega en la Argentina entre 1860 y 1960. Buenos Aires: Federación de Asociaciones Gallegas de la República Argentina. CD.

(2005c): Los Monfortinos. Entrada ao baile. Sarria: Ouvirmos VR0107. CD. (2009): Hermanos Moreira. Acordeón mariñeiro. Sarria: Ouvirmos VR0113. CD.

Martínez Blanes, Martín Gonzalo (2004): Manuel Quiroga \& Marta Leman. Pontevedra París 1912. Sarria: Ouvirmos VR0106. CD.

Os Furafoles (2011): FRFLS. Buenos Aires: Ed. Part. CD.

Xistra da Coruxo (1995): Se beillas arrente coidado cos terróns. Vigo: Do Cumio 1010. Casete.

\section{Referencias bibliográficas}

Biblioteca Nacional (1988): Catálogo de discos de 78 rpm. en la Biblioteca Nacional. Madrid: Ministerio de Cultura. 2 T.

Cámara de Landa, Enrique (2003): Etnomusicología. Madrid: Instituto Complutense de Ciencias Musicales. Cirio, Norberto Pablo (1999): "Domingo Ferreiro, O gaiteiro de Texas: unha historia para armar", Na Gaits 6, pp. 23-24.

(2003): "Perspectivas xeracionais na construción da identidade musical na colectividade galega da Arxentina", Estudios Migratorios 15-16, pp. 249-267.

(2005d): "Catálogo razonado de grabaciones comerciales de música gallega y vinculada a Galicia en la Argentina (2 tomos). Plan de la obra", Anuario da Gaita 20, pp. 97-100.

(2006): "Investigación musical y procesos migratorios. El caso de la colectividad gallega en la Argentina”, en G. Wilde y P. Schamber (comps.), Simbolismo, ritual y performance. Buenos Aires: SB, pp. $157-180$.

(2007): El romancero en la Galicia exterior. Cala de la colectividad gallega de la Argentina. Pontevedra: Deputación de Pontevedra.

(2011a): “Apuntes para la historia de la música celta en la Argentina”, en $\mathrm{M}^{\mathrm{a}}$ I. Pailleiro (comp.), San Patricio en Buenos Aires: narrativa, celebraciones y migración. Buenos Aires: Universidad de Buenos Aires, Facultad de Filosofía y Letras, pp. 59-74 del CD-ROM + 3 bandas de audio.

(2011b): "Las tarjetas de presentación de los conjuntos regionales gallegos de la Argentina como fuente de estudio", Anuario da Gaita 26, pp. 36-43.

_ (2013): "Panchito Cao, "El Gaitero de Texas": una historia armada", Anuario da Gaita 28, pp. 11-19.

__ (2014): "Producción musical de Manuel Dopazo Gontade (1882-1952)", Anuario da Gaita 29, pp. 17-30.

Comesaña Martínez, María Ángela (1999): Catálogo de la discografía gallega antigua en el Museo de Pontevedra. Pontevedra: Museo de Pontevedra.

Costa Vázquez, Luis (1998): “Coralismo, etnicidad y nacionalismo en Galicia”, Cuadernos de Música Iberoamericana 6, pp. 49-63. Madrid: Instituto Complutense de Ciencias Musicales.

_ (2001): "Etnicidade e nacionalismo: Música e galeguismo: extratexias de construcción dunha cultura nacional galega a través do feito musical", en X. M. González Reboredo (coord.), Etnicidade e Nacionalismo. Actas do Simposio Internacional de Antropoloxía. Santiago de Compostela: Consello da Cultura Galega, pp. 249-283.

(2004): "Las rumbas olvidadas: transculturalidad y etnización en la música gallega", Trans 8 (http:// www.redalyc.org/comocitar.oa?id=82200808).

Day, Timothy (2000): Un siglo de música grabada : Escuchar la historia de la música. Madrid: Alianza.

Elías, Guillermo César (2015): Historias con voz. Una instantánea fonográfica del Buenos Ayres a principios del siglo XX. Buenos Aires: Fundación Industrias Culturales Argentinas.

14 A fin de no abundar sólo cito la discografía analizada con cierto detalle. 
Estévez Vila, Xaime (2007): “As gravacións da música galega (1975-2000): Unha investigación de interese pedagóxico e cultural”, Etno-folk 7, pp. 79-92.

Feld, Steven (2000): “A Sweet Lullaby for Word Music”, Public Culture 12, pp. 145-171.

Frith, Simon (2003): "Música e identidad", en S. Hall y P. du Gay (eds.), Cuestiones de identidad Cultural. Buenos Aires: Amorrurtu, pp. 181-213.

García Muñoz, Carmen; Héctor Luis Goyena y Hernán Vigo (1999): “Fonografía (Argentina)”, en Diccionario de la Música Española e Hispanoamericana. Madrid: Sociedad General de Autores y Editores, vol. 5, pp. 190-192.

Kirshenblatt-Gimblett, Bárbara (1992): "El estudio del folklore de inmigración y étnico", Serie de Folklore 15 , pp. 39-56.

Leydi, Roberto (1989): "I dischi commerciali a 78 giri quali fonte documentaria per la conoscenza e lo studio della musica popolare", en D. Carpitella (ed.), Ethnomusicologica. Siena: Accademia Musicale Chigiana, pp. 127-141.

McLeod, Norma y Marcia Herndon (eds.) (1980): The Ethnography of Musical Performance. Norwood: Norwood Edition.

Martí i Pérez, Josep (1995): "La idea de 'relevancia social' aplicada al estudio del fenómeno musical", Trans 1 (http://www.sibetrans.com/trans/trans1/marti.htm).

(1996): "Música y etnicidad: una introducción a la problemática", Trans 2 (www.sibetrans.com/ trans/trans $2 /$ marti.htm).

Núñez Seixas, Xosé Manoel (2002): O inmigrante imaxinario: Estereotipos, representacións e identidades dos galegos na Arxentina (1880-1940). Santiago de Compostela: Universidade de Santiago de Compostela.

Ochoa, Ana María (2003): Músicas locales en tiempos de globalización. Buenos Aires: Norma.

Pelinski, Ramón (2000): Invitación a la etnomusicología. Quince fragmentos y un tango. Madrid: Akal.

Stokes, Martin (1994): "Introduction: Ethnicity, Identity and Music", en Ethnicity, Identity and Music. Oxford: Berg Publishers, pp. 1-27.

Tylor, Timothy D. (2001): Strange Sounds: Music, Technology and Cultures. New York: Routledge.

Valenciano, Ana (1998): Os romances tradicionais de Galicia. Catálogo exemplificado do seus temas. Madrid / Santiago de Compostela: Fundación Ramón Menéndez Pidal / Xunta de Galicia, Consellería de Educación e Ordenación Universitaria.

Varela Lenzano, Indalecio (1904): Los orfeones españoles en la República Argentina. Su pasado, presente y porvenir. Buenos Aires: Robles y Cía.

Wade, Peter (2000): Music, Race and Nation : Música Tropical en Colombia. Chicago: The University of Chicago Press. 